\title{
Physical activity cost of the school run: impact on schoolchildren of being driven to school (EarlyBird 22)
}

Brad Metcalf, Linda Voss, Alison Jeffery, Jenny Perkins, Terry Wilkin

University

Medicine, Peninsula

Medical School,

Derriford Hospital,

Plymouth PL6 8DH

Brad Metcalf

statistician

Linda Voss

senior research fellow

Alison Jeffery

research nurse

Jenny Perkins

nurse technician

Terry Wilkin

professor of

endocrinology and

metabolism

Correspondence to:

T J Wilkin

T.Wilkin@pms.ac.uk

BMJ 2004;329:832-3
Physical activity is perceived as important to children's health, and concern has been expressed at the increasing use of motorised transport to school-the "school run." We have measured the activity cost of the school run in young children in the EarlyBird study. ${ }^{2}$

\section{Participants, methods, and results}

We analysed data from 154 boys and 121 girls in their first year at 53 urban primary schools. The children wore uniaxial accelerometers (Manufacturing Technology, Florida) during waking hours for five consecutive schooldays and the weekend to measure physical activity. ${ }^{3}$ We considered activity during the journey to and from school (8 to 9 am and 3 to 4 pm weekdays), school time (9 am to $3 \mathrm{pm}$ weekdays), non-school time (before 8 am and after 4 pm weekdays), the total school week (weekdays), the weekend, and the total week. We measured height, weight, and body fat as the mean of five skinfolds. We found mode of transport and school journey time by questionnaire and distance to school with the RAC's online route planner. We used the National Statistics Socio-economic Classification to find socioeconomic status. Our study had 80\% power to detect a significant difference $(\mathrm{P}<0.05)$ of at least $12 \%$ in activity during the journey to or from school and at least $8 \%$ in total weekly activity.

Twice as many children walked to school (185/275; $67 \%$ ) as were driven by car, with no significant gender bias (97/154 (63\%) boys; 88/121 (73\%) girls; Pearson $\chi^{2}$ test $\mathrm{P}=0.12$ ). The median time taken to walk to school was 6 (interquartile range 5 to 10) minutes and the median distance was 0.7 (0.4 to 1.2$) \mathrm{km}$ with $155 /$ $185(84 \%)$ children walking less than a mile $(1.6 \mathrm{~km})$, comparable with the national figure of $82 \%{ }^{4}$

\section{What is already known on this topic}

The proportion of children travelling to school by car in the United Kingdom almost doubled from $16 \%$ in 1986 to $30 \%$ in 1998

There is a popular perception that being driven to school compromises physical activity

\section{What this study adds}

Being driven to school does not affect the overall physical activity of 5 year olds

Mean activity recorded during the 10 journeys to and from school was significantly higher during that period ( 0.75 units or $18 \%$ higher; $\mathrm{P}<0.001)$ among those who walked than those who travelled by car (table). However, total weekly activity was identical (difference 0.04 units or $0.1 \% ; \mathrm{P}=0.97$ ). Crucially, the additional activity recorded by walkers during the school journey was only $2 \%(0.75 / 37.6)$ of the children's total weekly activity.

Although the proportion of walkers was highest in the lowest socioeconomic group (C 65/82 (78\%); B $49 / 78$ (63\%); A 71/115 (62\%); $\mathrm{P}=0.02)$, the pattern of results was unchanged when we analysed each social group in turn (data not given). Analysis of only moderate and high intensity activity gave consistent results. The two groups did not differ significantly in either body mass index (walk $16.1 \mathrm{~kg} / \mathrm{m}^{2} v$ car $16.2 \mathrm{~kg} / \mathrm{m}^{2}$;

This article was posted on bmj.com on 18 August 2004: http://bmj.com/ cgi/doi/10.1136/bmj.38169.688102.F71

Physical activity during a week comparing children who walked to school with those who travelled by car recorded by 275 children according to mode of transport. Values are mean accelerometer count $\left(\times 10^{5}\right)$ (standard deviation) unless stated otherwise

\begin{tabular}{|c|c|c|c|c|c|c|c|c|c|}
\hline & \multicolumn{3}{|c|}{ All children } & \multicolumn{3}{|c|}{ Boys } & \multicolumn{3}{|c|}{ Girls } \\
\hline & Walk $(n=185)$ & Car $(n=90)$ & P value* & Walk $(n=97)$ & Car $(n=57)$ & P value* & Walk $(n=88)$ & Car $(n=33)$ & $P$ value* \\
\hline Age (years) & $4.93(0.26)$ & $4.91(0.26)$ & 0.50 & $4.95(0.27)$ & $4.92(0.25)$ & 0.40 & $4.91(0.26)$ & $4.90(0.27)$ & 0.86 \\
\hline \multicolumn{10}{|l|}{ All intensities } \\
\hline School journey (8-9 am and 3-4 pm) & $4.90(1.41)$ & $4.15(1.19)$ & $<0.001$ & $4.92(1.24)$ & $4.30(1.12)$ & 0.003 & $4.88(1.57)$ & $3.88(1.28)$ & 0.001 \\
\hline School time (9 am-3 pm) & $12.75(3.13)$ & $12.37(3.23)$ & 0.35 & $13.51(3.35)$ & $13.10(3.04)$ & 0.45 & $11.91(2.64)$ & $11.11(3.20)$ & 0.17 \\
\hline $\begin{array}{l}\text { Non-school time (<8 am and }>4 \text { pm } \\
\text { weekdays) }\end{array}$ & $9.07(3.00)$ & $9.75(3.14)$ & 0.08 & $9.14(3.27)$ & $9.95(3.08)$ & 0.14 & $8.98(2.68)$ & $9.41(3.25)$ & 0.47 \\
\hline Total school week (weekdays) & $26.71(5.64)$ & $26.27(5.31)$ & 0.53 & $27.57(6.04)$ & $27.35(4.88)$ & 0.82 & $25.77(5.03)$ & $24.40(5.58)$ & 0.20 \\
\hline Weekend (Saturday and Sunday) & $10.79(2.92)$ & $11.30(3.04)$ & 0.19 & $10.94(2.99)$ & $11.52(3.09)$ & 0.26 & $10.62(2.84)$ & $10.91(2.95)$ & 0.63 \\
\hline Total & $37.56(7.74)$ & $37.60(7.33)$ & 0.97 & $38.44(8.26)$ & $38.87(6.89)$ & 0.74 & $36.56(7.01)$ & $35.34(7.64)$ & 0.41 \\
\hline \multicolumn{10}{|l|}{ Moderate and high intensities onlyt } \\
\hline School journey (8-9 am and 3-4 pm) & $3.75(1.42)$ & $2.95(1.18)$ & $<0.001$ & $3.77(1.24)$ & $3.12(1.13)$ & 0.001 & $3.74(1.61)$ & $2.66(1.23)$ & 0.001 \\
\hline School time (9 am-3 pm) & $9.05(3.12)$ & $8.70(3.22)$ & 0.38 & $9.87(3.37)$ & $9.46(2.97)$ & 0.45 & $8.16(2.54)$ & $7.39(3.24)$ & 0.17 \\
\hline $\begin{array}{l}\text { Non-school time (<8 am and }>4 \text { pm } \\
\text { weekdays) }\end{array}$ & $6.69(2.75)$ & $7.25(3.00)$ & 0.12 & $6.81(3.02)$ & $7.55(2.98)$ & 0.14 & $6.55(2.43)$ & $6.74(3.02)$ & 0.72 \\
\hline Total school week (weekdays) & $19.50(5.54)$ & $18.90(5.36)$ & 0.40 & $20.45(5.98)$ & $20.13(4.93)$ & 0.73 & $18.44(4.82)$ & $16.79(5.48)$ & 0.11 \\
\hline Weekend (Saturday and Sunday) & $8.13(2.94)$ & $8.62(3.05)$ & 0.21 & $8.34(3.05)$ & $8.92(3.14)$ & 0.26 & $7.90(2.80)$ & $8.09(2.86)$ & 0.75 \\
\hline Total & $27.65(7.68)$ & $27.55(7.46)$ & 0.91 & $28.70(8.27)$ & $29.05(7.09)$ & 0.80 & $26.46(6.81)$ & $24.88(7.45)$ & 0.28 \\
\hline
\end{tabular}

${ }^{*}$ The $\mathrm{P}$ values are based on $F$ statistics obtained from one way analysis of variance

tExcluding low intensity activity where counts/min $=<1000$. 
$\mathrm{P}=0.88$ ) or sum of skinfolds (walk $4.10 \mathrm{~cm} v$ car 3.93 $\mathrm{cm} ; \mathrm{P}=0.28$ ).

\section{Comment}

Although children who walk to and from school record more activity in the process, the difference has no impact on total weekly activity. Those driven by car matched those who walked to school in overall activity levels. These results apply to 5 year olds, but the EarlyBird study is longitudinal and ideally designed to compare findings once the children move from primary school to secondary school.

Another study to have considered the impact of walking to school on physical activity in children reported that boys (though not girls) who walk to school are more active after school. ${ }^{5}$ However, measurement of after school activity included the walk home, making the analysis difficult to interpret. Curiously, girls who walked recorded no more physical activity in so doing than those who were driven. The patterns of activity in the present study were systematically the same for girls and boys, lending further robustness to our findings.

Whether children walk to and from primary school makes no difference to their total activity. This does not justify the adverse publicity given to the school run nor the government's perception of the school run's impact. There may be other benefits from walking children to their neighbourhood school, but physical activity does not appear to be one of them.

Contributors: TW conceived the study, supplied the hypothesis, edited the manuscript and is guarantor. LV conceived the study and edited the manuscript. BM performed the analysis and wrote the manuscript. AJ and JP recruited the subjects and collected all data.

Funding: Diabetes UK, Smith's Charity, S\&SW NHS Executive R\&D, Child Growth Foundation, Beatrice Laing Foundation, Abbott, Astra-Zeneca, GSK, Ipsen, Unilever, Diabetes Foundation, EarlyBird Diabetes Trust.

Competing interests: None declared.

Ethical approval: Plymouth local research ethics committee of the South and West Devon Health Authority (1999).

1 Department for Education and Skills and Department for Transport. Travelling to school: a good practice guide. London: DfT, 2003. www.teachernet.gov.uk/_doc/5172/DfT-good\%20practice\%20guide.pdf (accessed 1 Jul 2004).

2 Voss LD, Kirkby J, Metcalf BS, Jeffery AN, O'Riordan C, Murphy MJ, et al. Preventable factors in childhood that lead to insulin resistance, diabetes mellitus and the metabolic syndrome: the EarlyBird diabetes study $1 . J$ Pediatr Endocrinol Metab 2003;16:1211-24.

3 Metcalf BS, Curnow JS, Evans C, Voss LD, Wilkin TJ. Technical reliability of the CSA activity monitor: the EarlyBird study. Med Sci Sports Exerc 2002;34:1533-7.

4 Department of the Environment, Transport, and the Regions. National travel survey: update 1997/99. London: Stationery Office, 2000.

5 Cooper AR, Page AS, Foster LJ, Qahwaji D. Commuting to school: are children who walk more physically active? Am J Prev Med 2003;25:273-6. (Accepted 24 May 2004)

doi 10.1136/bmj.38169.688102.F71

\section{Endpiece}

\section{The best physician}

The best physician, one fit to treat a king, is he whose knowledge is fourfold: the cause, symptom, cure, and non-recurrence of disease.

The Carakaa Samhita (ancient Indian text)

Sonal Singh, Unity Health System, Rochester, New York

\section{A memorable patient}

\section{And a memorable day}

It was January 1956 and the day on which I was to undertake the final part of "Conjoint surgery, clinical and viva." I presented myself at Queen's Square and was conducted into the examination hall to meet my "long case." He was a cheerful Cockney who, I realised, was no stranger to Queen's Square. With the minimum of fuss, he told me his history and his diagnosis: "It was a TB hip, doc." Only a couple of weeks previously I had examined such a case in the outpatients clinic.

I completed the details of the history before embarking on the examination, and when I had finished I thought that I had covered everything.

"What have you found, doc?"

Briskly, and with all the confidence of youth, I reeled off the findings.

"OK, but what about telescopic movement?"

Although I had observed shortening on the affected side, was this something that, in my haste and misplaced zeal, I had forgotten? Quickly, and with the examiner coming towards me, I measured it and found about 2 inches of shortening. I gave the history and findings to the examiner, but I must say when I mentioned telescopic movement I saw a hint of a smile cross the patient's face.

The short cases seemed to be straightforward, and so I went on to the royal college for the viva. When all this was over there was about two hours to wait before the results were announced.
All the candidates, some hundred in number, gathered in a hall to learn their fate. At 5 pm a college porter, resplendent in his uniform, appeared and called out each candidate individually, checking each identity by examination number and by name. Those who had been successful, of whom I was one, were invited to go upstairs to be congratulated by the examiners. This was a wonderful tradition but not without stress, particularly for those who failed and had to slink downstairs and away in the night.

I travelled home to Yorkshire to acquaint my parents with my success and to tell my long suffering fiancée that we could at last get married, notwithstanding the fact that I should earn only $£ 415$ a year-a sum far short of her earnings.

Bryan Scaife retired family doctor, Ingleby Barwick, Stockton on Tees

We welcome articles up to 600 words on topics such as A memorable patient, A paper that changed my practice, My most unfortunate mistake, or any other piece conveying instruction, pathos, or humour. Please submit the article on http://submit.bmj.com Permission is needed from the patient or a relative if an identifiable patient is referred to. We also welcome contributions for "Endpieces," consisting of quotations of up to 80 words (but most are considerably shorter) from any source, ancient or modern, which have appealed to the reader. 